\title{
Post-surgical mental morbidity of breast cancer survivors in India: reflection from urban Gujarat
}

\begin{abstract}
Introduction: Breast Cancer $(\mathrm{Ca})$ is one of the most common cancers amongst women globally as well in India. With increasing awareness and available diagnostic facilities, it is expected to increase further. One of the main stay of treatment is surgical excision of the tumor, there are ample literature on types of surgery, post surgical survival rates, health related morbidity etc. However, there is very limited research on the Post Surgical Mental health status of survivors. The present study focuses on documenting the psychological impact of mastectomy especially from urban India and also explores the insight into need for Pre and Post mastectomy counselling not only for the survivors but also for the household and family members.
\end{abstract}

Method and materials: Qualitative methods mainly In-depth Interviews were conducted amongst females of $\mathrm{Ca}$ Breast who underwent mastectomy in urban area of Ahmadabad, Gujarat (India). Snow Ball sampling was used for identification of the Cases. The inclusion criteria was Married, Post Mastectomy survivors (more than a year) and residing in Ahmadabad. The tool used was pilot tested and Interviews were analyzed using Atlas Ti software.

Results: The observations were clubbed into major themes, Denial/fear to diagnosis and Surgery, Pre and Post Surgical Experience and Mental Stress due to perception of loss of femininity, Fear of rejection and separation from husband. There was also fear of relapse causes anticipatory waiting for next checkup and Coping Mechanism. Strong social support, high family functioning are reported to be positive personal resources for coping while loss of femininity and fear of rejection by husband was the most stressful and a major cause of mental morbidity.

Conclusion: Present study explores and documents mental morbidity and psychological stress that the survivors of Breast cancer face from the time since the cancer is diagnosed to rest of the life. With the incidence increasing, there is an urgent need for counselling for both patients and family members especially spouse.

Keywords: cancer, breast, mental, health, mastectomy, diagnosed, documents, counselling, mortality, women
Volume 7 Issue 6 - 2018

\author{
Deepak Saxena,' Poonam Trivedi,' Deepika \\ Singhal ${ }^{2}$ \\ 'Indian Institute of Public Health Gandhinagar, India \\ ${ }^{2}$ GMERS Sola, India
}

Correspondence: Deepak Saxena, Indian Institute of Public Health Gandhinagar, Palaj Village, Lekawada Cross road, India, Tel +91-9327396717, Email ddeeqak72@iiphg.org

Received: Januvary 30, 2017 | Published: December 18, 2018
Abbreviation: CA, cancer; HM, mental health; NGO, Non-Governmental Organisation

\section{Introduction}

Breast cancer ranks as the fifth cause of mortality from cancers and the most frequent cause of cancer deaths in women in developing regions. The incidence of $\mathrm{Ca}$ Breast is rising in India and has overtook cervical cancer as the most common type of cancer amongst all women and becomes the most common cancer diagnosed in women with a mortality rate of 12.7 per lac population. ${ }^{1}$

Diagnosis of any chronic illness especially cancer frequently results in a complex set of issues that the individuals must confront. These issues affect social, financial and also mental well being of the patient. Cancer treatment also leads to lot of health issues and treatment-related symptoms which may persist for a long time and may add distress to patients who are under great pressure to cope with the demands of their disease and treatment. Patients and their relatives are also challenged in their interpersonal relationship, dealing with the stress and the demands caused by cancer. ${ }^{2}$ with rapid advancement in diagnosis and treatment of cancer leads to increase of survival rate of patients hence, there is an urgent need for implementation of mental and physical rehabilitation services for providing quality care. In addition to physical stress, breast cancer patient faces various psychological problems and mental stress leading to many emotional disorders such as anxiety, tension, depression, grief, hopelessness, helplessness and high degree of passivity. ${ }^{3}$ Moreover, there are studies narrating that mastectomy causes more trauma than the cancer illness itself. ${ }^{4}$ Majority of the research is limited to diagnosis and treatment, with very few publications dedicated to patient's psychological needs after mastectomy. ${ }^{5}$ Given increasing trend of the disease in India, studies that address the psychological need of breast cancer survivors who underwent mastectomy are required in order to understand the specificity and needs. Present study documents Mental health status mainly psychological experiences that a women faces during the diagnosis and their post surgical coping mechanism.

\section{Material and methods}

Present study was conducted in urban area of Ahmadabad 
Municipal Corporation, Gujarat-India. The inclusion criteria were;

a) Married in reproductive age group

b) Residing in Ahmadabad

c) Survivor of Mastectomy for more than a year

d) Total/Partial/Unilateral/Bilateral Mastectomy

Qualitative methods were used (mainly In-depth interviews). The index woman was identified from tertiary care hospital of Ahmadabad and subsequent participants were identified by snowball sampling technique. The number of participants to be included in the study was based on the criterion of data saturation, where the information being analyzed became recurrent and repetitive. Women were interviewed at their household level. Written informed consent was sought from the participants. All interviews were conducted in local vernacular language and audio recorded with adequate privacy. Interviews were than transcribed and translated in English. Interviews were analyzed using Atlas TI software.

\section{Results and discussion}

\section{Participant's profile}

A total of Six women who underwent (partial or total mastectomy and were surviving for more than a year after surgery were interviewed. Only those who agreed to participate voluntarily in the research and signed the prior informed consent form were recruited. The participants aged between 40 to 69 years and married and living with spouse. As per the occupation, three women were housewives; one was a trained physician, whereas rest two was retired school teachers. All were literate and had completed graduation or more. Out of Six, Five had one or more kids, whereas one had never conceived.

Following themes emerged from the in-depth interviews.

a) Denial and Fear: Journey since first symptom to confirmation of diagnosis

b) Fear of loss of feminity

c) Pre and Post Surgical relationship with spouse, kids and family

d) Pre and Post Surgical relationship with colleagues at work place

e) Reflection on way forward

\section{Denial and fear}

Journey from appearance of first symptom to confirmation of diagnosis. The appearance of first symptom in majority of participant was experiencing lump in the breast or in arm pit. Majority of them initially discussed this with the spouse and waited for duration of 3 to 6 months before seeking advice from trained professional. In present study, the suspected/probable diagnosis of lump being a cancer was perceived as a shock. The confirmatory diagnosis of lump being described as the most stressful time in their life. All the respondents contacted more than 3 health care experts ranging from Physicians/ Surgeons and Obstetricians. This reflects a denial to the situation of being diagnosed as cancer patient. The investigations ranged from routine mammography to diagnostic biopsy. The females reacted differently to the situation, majority of the females accepted disease as their fate, some suppressed their reaction and some females blamed karma (God) for their problem. As narrated in quote below: "Why this has happened to me only? I usually pray to God almost every day. Why God has given this disease to me? The denial for diagnosis and its rejection by spouse and household members was also strong. One of the women shared. I and my husband cried a lot on that day, but my husband was sure this cannot be cancer. He went on scolding the poor skills of the treating doctor and apparently felt that doctor wanted to snatch money and has given false diagnosis "Another woman took the diagnosis very positively and narrated in quote: "I am happy that it was detected in early stages and I survived. There are many around me with various chronic health issues like Diabetes, Hyper tension, so I am also having a chronic disease that's it". On inquiring the most common fear, almost all of them shared that at the time of diagnosis, they felt that they are going to die very soon. "I felt like only few days left for me, I was concerned as my son has completed just 10 years, I love my family and was depressed on learning that what will happen to my family once I die". There are similar observations from a previous research narrating significant psychosocial impact of the cancer diagnosis on younger women. They experienced being in a rollercoaster of emotions, were distressed and felt insecure. ${ }^{6}$ Almost all the participants denied family counselling as well as self counselling by a trained designated counsellor. Majority of them shared that the treating doctor was the source of counselling and majority of time it was only information sharing session. One of the participants narrated: "I asked my doctor about some more information or female who can tell me about the course of disease as my doctor was a male; he narrated no one better than a doctor can give appropriate information". All of them felt need for patient counselling and counselling of the family especially spouse. One of the participants shared: "The only thing I needed during my disease was someone to hold my hand and hear me for half an hour; my doctor was focused on learning doses, side effects, pains and symptoms". "He never asked about me".

\section{Fear of loss of feminity}

The scientific literature is rich in accounts of the loss of a body part being experienced as harm to the self-image and therefore, affecting the psychic condition of the person affected, triggering a painful process of mourning. ${ }^{7}$ According to the literature, surgery for removal of tumor mass does not only change just the body image of women, but also their self-image. ${ }^{8}$ Mastectomy, as a breast removal, involves the loss of worthy image, which is not observed in the surgical treatment of any other tumors. It not only affect self-image but also in relation to others and surroundings. In present study, the loss of the breast as experienced by women was the most stressful situation, she felt that she no longer looks beautiful and there was a denial for surgery due the fear of scars and disfigurement. One of the respondent shared that, "Initially, I refused for surgery because if my breast will be removed there will be permanent scar and disfigurement of my body. I will lose my identity and women hood".

One of the respondent narrated that post surgery when she was put on chemotherapy, it lead to hair loss and was terrible: "After Surgery, they staretd giving me drugs both oral and intra muscular, within few days I almost became bald and was forced to use wig, I was so depressed and felt like committing suicide, my husband always loved my long hair, I felt he was very sad to see me in this condition". One of the respondent opined that she tried to delay initiating the treatment because of fear of loss of hair due to chemotherapy and narrated: "Previously, I never wanted to be on chemotherapy because, I have 
heard that due to chemotherapy, there is severe hair loss but I had no choice except to follow the instructions, it was a horrible stage of my life and I want to forget the same." Almost all subjects reported that after the diagnosis; when Surgeon shared about removal of breast, the first reaction from the spouse was to seek information about the experience of other patients (survivors) who underwent the surgery and to inquire about the consequences of treatment. Initially few of the subjects felt confused about the request of spouse to meet with survivors, but after talking with them, they felt good, hopeful and confident. "We met the patients who underwent mastectomy. They gave me strength as few of them underwent surgery almost before 10 years. After talking with them I also came to learn about various consequences that I might have to pass through during the treatment and this helped me immensely to prepare myself for treatment".

\section{Pre and Post Surgical relationship with spouse, kids and family}

Influence from family and social support plays both positive and negative roles. For women one of the strongest strength is warmth, love and support she receives from the family and household members. On one hand family gives strength and confidence to the patients and on the other hand their reaction can sometime lead to negative feelings. Participants shared anecdotal experiences, about the reaction of the family members sometimes very sympathetic and at times very annoying. "My husband always was afraid that my younger daughter should be kept away from me as he feared she might also get the disease, this was painful. To add to my agony, my motherin- law in fact started counselling me about possible second marriage of my husband in case I could not survive". One of the participants shared that in-spite of almost 3 years post-surgery, even common cold or fever is related with cancer breast. "My family is so concerned that even fever and cough and cold are due to my three year old disease to other organs, I have no choice except to live with this suspicion for whole of my life". Few of the participants shared some positive relationship with spouse after surgery, one of the subjects shared: "My husband was the force of my early recovery, he left no stone unturned to keep me happy and to receive the best of treatment". One of the participants shared "I was afraid, how my husband will react to my scars and loss of hair as I am not attractive; but my husband supported me well and give me strength to go for further treatment". A similar qualitative study on stressor in breast cancer reported that the positive approach by family assists in better recovery. ${ }^{7}$ It was also observed that patients who had good support of family, cope up with the situation well on other side patient who had no kids felt fear and depression. This finding highlights importance of family support and role of support group. One of the participant shared that, " before disease I was happy with my spouse, in spite of not having a kid but now after surgery, I feel alone and very frequently I get negative thoughts and afraid of losing my spouse ; he has more than one reason to look for alternatives". A similar study found that, the women who had responsibility of their children and family members, they showed positive coping to shield their families due to their responsibilities towards their children. ${ }^{6}$ In present study participants shared that they have responsibilities of children and whole family so they need to be strong, despite of being fragile in order to minimize their concerns. "I have stopped worrying about my illness because entire responsibility of my family lies on me. My mother in law is not well so, I need to take care of her. If, I look depressed or cry, my family members will also feel sad. I also know if I start taking tension about my illness, me and my family health will also deteriorate".

\section{One of the participants shared}

"My family will be broken if, I am not there and this is the major concern of mine. So I show myself strong and cope up with this disease for the safety of my family and my children".

\section{Pre and post surgical relationship with colleagues at work place}

The present study also documented the Pre and Post-Surgical relationship with colleagues at work place. Only One of the participant was working out of the Six enrolled in present study. She felt the colleagues at her work place were sympathetic to her during the course of illness. Although, she often felt that colleagues are discussing about her and her appearance. "Once I resumed my job, colleagues were more or less sympathetic, however, I often caught them whispering about me; possibility my looks, which made me uncomfortable". Her mental stress at workplace can be reflected on the statement given below: "Given an option, I would like to quit the job and do some social, charity work, I wish I can do that but I need money to survive, more money in present circumstances".

\section{Way forward}

Majority of the participants were aware about the possibility of spread of the cancer to different organs including the other breast, hence always feels a sense of insecurity. One of the participants shared: "My doctor has already informed me that there can be spread of disease to other organ and so nothing is full proof, I am always scared and stressed". On inquiring about how best they can help the community in spreading awareness about breast cancer, majority except one were reluctant to go out in public for spreading awareness in general community but were keen to assist someone with similar cancers. Almost all of them were aware about presence of NGO/ Civil Societies working on Cancer but were not aware about any one specifically working on Breast cancers.

\section{Discussion}

Present study identifies the important aspects of the status of mental morbidity and psychological needs of females who underwent mastectomy. Majority of them shared time at diagnosis as the most stressful phase. Females perceive surgery as a permanent loss of feminism. The study also highlights loss of breast and loss of hair as a metaphor for loss of feminism. Participants had a strong fear of being rejected by spouse and separation from family. Family members and spouse can play both positive and negative roles in the coping up mechanism, post surgery. Although India does not have a formal registry of breast cancer survivors but the role of peer support group in the present study was identified as an important factor in relieving the stress participants who contacted with peers who underwent mastectomy shared that it helped them to prepare themselves for surgery and further consequences.

One of the intense fear amongst survivors is that of relapse which causing anticipatory waiting for next checkup. The combination of all these factors leads to feeling of helplessness with mental stress. Inspite of being vulnerable and in need, there are no formal mechanism of seeking assistance from counsellors and hence surgeons or treating doctors take up the role of counsellors. But the surgeons/or treating doctors are more focused on providing information rather than being empathetic to women. It was also documented that women having good family support cope up well as compared to the women who live alone 
having little social support. More so, it was found that responsibility of family helps in coping, as women shield their emotions due to concerns of their children and family. Previous studies also support this finding that, amongst psychosocial factors, factors relating to patient's environment such as social support and family functions, and problem solving or coping styles were highly associated to anxiety and depressive disorders. ${ }^{9}$ Strong social support, high family functioning, and adaptive problem-solving patterns are reported to be positive personal resources. These resources are considered as the protective factors which help to moderate psychosocial stress and lessen psychiatric morbidities. Previous studies show that strong social support, high family functioning, and adaptive problemsolving patterns reduced the psychiatric morbidities such as anxiety and depressive disorders in breast cancer patients. ${ }^{9}$ Present study offers an important insight into the Mental Morbidity of Post Surgery breast cancer survivors in developing countries. Understanding these factors can assist in planning of effective treatment and can result in successful treatment outcomes. However, as the study is based on qualitative methods, one of the major limitations is regarding generalizability of observations. Studies based on quantitative methods with appropriate mental score tools, would be useful for external validity and generalizability.

\section{Conclusion}

Mastectomy continues to be practiced as the first line of management of Carcinoma Breast. ${ }^{4}$ Present study documents the Mental Morbidity and Psychological needs of female who underwent mastectomy. There is fear of loss of femininity and turbulent relationship with the spouse along with fear of life threatening consequences. All these need an urgent intervention by a trained counsellor, which is found missing in the current health programs for Cancer rolled out in India. Counselor can play important role in cancer health programs for reducing pain and psychological morbidities. Presently in India more emphasis is given to the treatment and diagnosis of cancer patients however, the quality of life and psychological need of women have not received considerable attention which is equally important and meaningful as the survivors of cancers are going to increase in coming year. Present study suggests involvement of husband, family members and peer support groups, who can play an important role in coping up from cancer. Promoting patients' social support, especially emotional support from family and enhancing patient's coping skills may reduce the patient's Mental Morbidity and psychological stress. The result of this study reinforces the need to consolidate physical, social and mental rehabilitation to ensure support and care to cancer survivors.

\section{Acknowledgment}

Authors are thankful to the participants of the study for their active involvement and support for the study activities.

\section{Conflicts of interest}

The authors declare that they have no competing interests.

\section{References}

1. Park K. Epidemiology of chronic non communicable diseases and condition. In: Park's textbook of preventive and social medicine. 23rd ed. 2014. 868 p.

2. Buchi S. Pasychological needs of breast cancer patients and their relatives. J Clin Nurs. 2008;17(21):2895-2909.

3. Khan MA, Bahadur AK, Agarwal PN, et al. Psychological disorder in women undergoing postoperative radiation and chemotherapy for breast cancer in India. Indian journal of Cancer. 2010;47(3):296-303.

4. Arroyo MG, Lopez MLD. Psychological problems derived from mastectomy: A qualitative study. International Journal of Surgical Oncology. 2011. 8 p.

5. Hack TF, Degner LF. Coping responses following breast cancer diagnosis predict psychological adjustment three years later. Psychooncology. 2004;13(4):235-247.

6. Coyne E and Borbasi S. Holding it all together: Breast cancer and its impact on life for younger women. Contemporary Nurse. 2006;23(2):157169.

7. Silva Gisele da, Santos Manoel Antônio dos. Stressor in breast cancer post treatment: a qualitative approach. Latin American Journal of Nursing. 2010;18(4):688-695.

8. Rossi L, Santose MA. Psychological repercussion of illness and treatment for women affected by Breast Cancer. Psycho Cienc Prof. $2003 ; 23(4): 32-41$.

9. Lueboonthavatchai P. Prevalence and psychosocial factors of anxiety and depression in breast cancer patient. Journal of Medical Association Thai. 2007; 90(10):2164-2174. 